\title{
Joining Alumina to the TZM Alloy by Hot Pressing
}

\author{
A two-step process was used to produce a strong joint \\ between alumina and the titanium-zirconium-molybdenum alloy
}

BY R. BERKOUCH, S. VALETTE, J. ABSI, AND P. LEFORT

\begin{abstract}
A strong joint ( $>45 \mathrm{MPa}$ ) was obtained between alumina and the titanium-zirconium-molybdenum alloy (TZM) via a two-step process. First, by the controlled oxidation of the alloy in air, and then by hot pressing. After the first step, the pieces were only weakly bonded, and the surfaces of TZM and alumina became irregular, with a complex oxide interlayer. After hot pressing, the oxides quasi entirely disappeared from the interface, but the oxide $\mathrm{MoO}_{2}$ remained in a few places. Under the pressure effect, $\mathrm{MoO}_{2}$ penetrated inside $\mathrm{Al}_{2} \mathrm{O}_{3}$, while the sintering additives of alumina migrated inside the TZM. The strength of the junction was considered to be due both to a mechanical contribution and to the effect of the secondary phases that crossed the interfacial zone. The adherence of the assemblies was not yet determined because of ruptures in the glue during the adhesion test ASTM C633-13.
\end{abstract}

\section{KEYWORDS}

- Ceramic-to-Metal Joining • Hot Pressing

- Oxidation • Molybdenum • TZM • Alumina

\section{Introduction}

The new uses of ceramic/metal assemblies in severe conditions require joining compatible with high temperatures and aggressive environments, together with good mechanical properties. The main processes providing high-quality ceramic-to-metal assemblies implement diffusion joining.

Now, the first difficulty comes from the fact that diffusion joining between the metal $\mathrm{M}$ and the ceramic such as the oxide $\mathrm{M}_{\mathrm{x}} \mathrm{O}_{\mathrm{y}}$ is only possible if some mixed compound can be formed (e.g., $\mathrm{M}_{\mathrm{p}} \mathrm{M}_{\mathrm{q}}^{\prime} \mathrm{O}_{\mathrm{z}}$ ), which signifies that the ceramic must react with the metal; however, such reactions are thermodynamically impossible for ceramic/metal couples having potential applications. Indeed, to summarize quickly, for giving rise to a reaction, $\mathrm{M}$ must be less electronegative than $\mathrm{M}$ ', which is generally true only for alkaline or alkaline earth metals, without any application as structural materials (Ref. 1). The most widely spread method for the diffusion joining route, is moly-manganese brazing (Ref. 2). These processes have been known for a long time (Ref. 1), but they imply complex and multiple steps that require much know-how. In these processes, the added interlayers play a double role:

1) They react with both metal and ceramics, giving the diffusion joining, and

2) They play the role of a buffer zone that accommodates the stresses due to the difference in thermal expansion coefficients (TECs). Indeed, the TECs of metals are generally significantly higher than those of ceramics, and intense shear stresses appear during thermal cycling, which weakens the junctions.

Unfortunately, these interlayers have relatively low melting points, or produce eutectics with rather low melting points: This prevents any use of such assemblies at high temperatures.

The choice of materials to be joined is also limited for high-temperature applications; in particular, the metals must have high melting points. In this respect, molybdenum $\left(\mathrm{T}_{\mathrm{F}}=2610^{\circ} \mathrm{C}\right)$ is a good candidate with excellent structural properties for applications requiring high strength and rigidity up to $1650^{\circ} \mathrm{C}$. Unfortunately, molybdenum oxidizes in air from about $300^{\circ}$ to $400^{\circ} \mathrm{C}$, which imposes working in protective atmospheres, except when the duration of use is relatively short, i.e., in some military applications. Instead of pure molybdenum, the titanium-zirconium-molybdenum (TZM) alloy (Mo99/Ti0.5/Zr0.1 at.-\%) is often preferred because it has a higher recrystallization temperature (about $1400^{\circ} \mathrm{C}$ ) and better tensile strength, for a high melting point of $2620^{\circ} \mathrm{C}$. Moreover, its TEC is close to that of many ceramics $\left(7-9 \times 10^{-6} \mathrm{~K}^{-1}\right)$.

For these reasons, (TZM) was chosen for testing a process of junction that has already been successfully tested for the junctions steel C35/alumina (Ref. 3). This process involved preoxidation of the alloy before the joining treatment. In the continuity of these works, the selected ceramic was again alumina, which is not very expensive and keeps good mechanical properties up to about $1600^{\circ} \mathrm{C}$.

It may be noticed that assemblies of $\mathrm{Mo} / \mathrm{Al}_{2} \mathrm{O}_{3}$ have already been tested for a long time (Ref. 4) by using hard brazing processes, but these processes presented several major disad- 


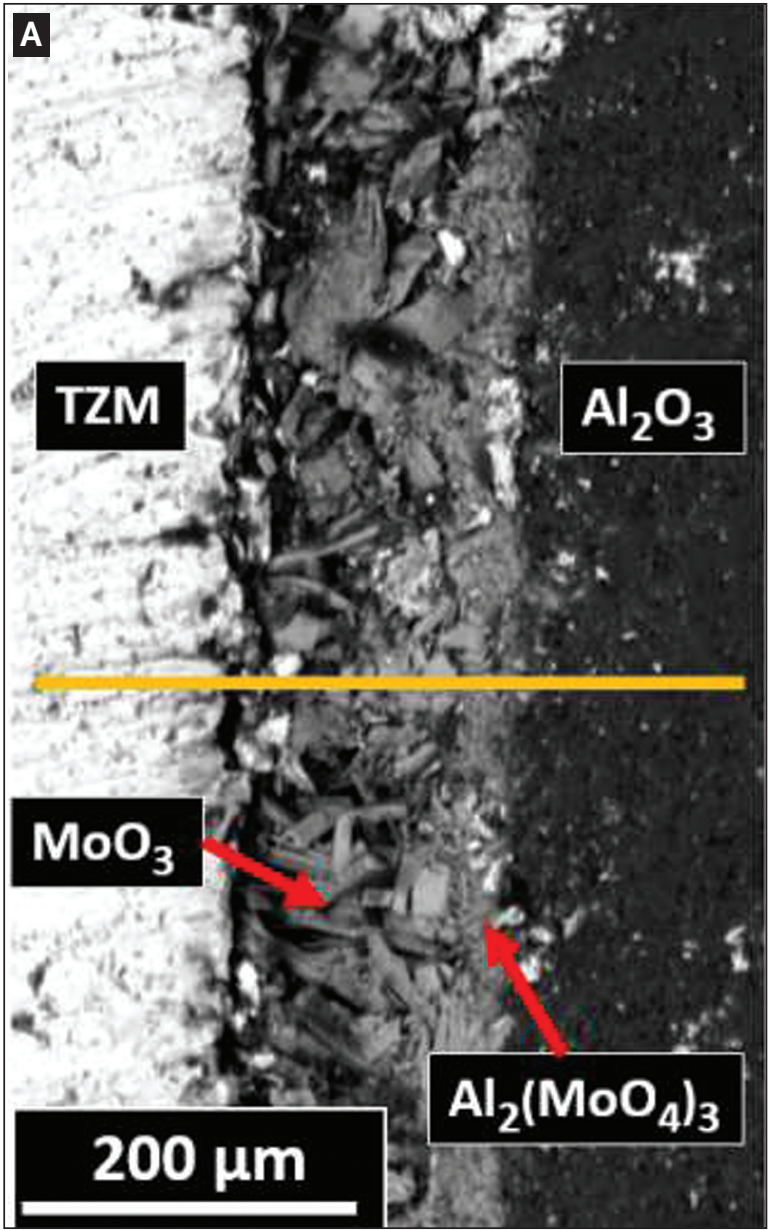

vantages. When the filler alloys contained titanium as a reactive element, the assemblies had rather low mechanical characteristics (Ref. 5) except when the ceramic was in a ceramicreinforced metal matrix composite (Ref. 6); with moly-manganese processes, the results were better, but the temperature of use remained relatively low (no more than $700^{\circ} \mathrm{C}$ ) and, furthermore, this process cannot be used with alumina of high purity (> 99\%) (Ref. 7). The alternative method for joining alumina to TZM described here comprises only two steps: the alloy preoxidation and the hot-pressing (HP) treatment. This method was recently presented (Ref. 8), and the main purpose of the present work is to complete and explain the joining mechanisms of this new process.

\section{Experimental Procedures}

The process used needs neither interlayer nor metallization, but the simple surface oxidation of TZM in air, followed by HP. The preoxidation step aims to form the interlayer necessary for obtaining diffusion joining. From the thermodynamic point of view, it was verified that not any reaction was possible between the alloy elements of TZM

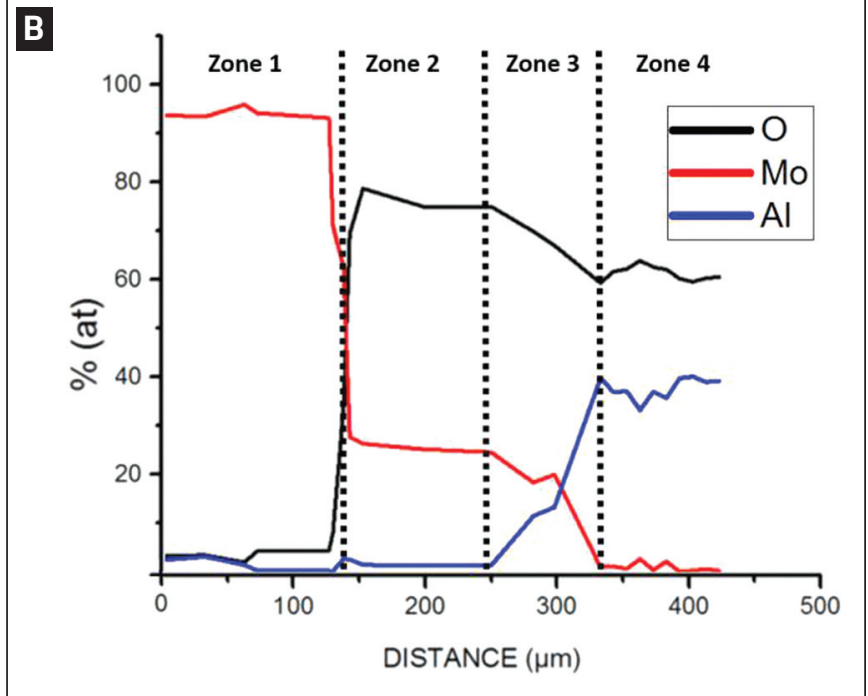

Fig. 1-BSE micrograph of the TZM/alumina assembly, in cross section, after the following: $A-A 30$-min treatment at $795^{\circ} \mathrm{C}$ in air; $B-E D S$ analysis following the line of the micrograph.

and alumina, whatever the temperature.

For instance, Equation 1 corresponds to the reaction of molybdenum with alumina that gives $\mathrm{MoO}_{3}$ :

$$
\mathrm{Al}_{2} \mathrm{O}_{3}+\mathrm{Mo}=2 \mathrm{Al}+\mathrm{MoO}_{3}
$$

corresponds to a Gibbs function (calculated on the basis of Barin Thermodynamical data [Ref. 9]) $\Delta \mathrm{G}$ with positive values for all temperatures, e.g., $\Delta \mathrm{G}=768 \mathrm{~kJ}$ mol-1 at $1700 \mathrm{~K}$. This confirms the well-known fact that a direct reaction between molybdenum and alumina is not thermodynamically possible (Ref. 10).

The samples used were discs $(10 \mathrm{~mm}$ in diameter, $3 \mathrm{~mm}$ thick) cut with a circular saw in TZM and alumina rods (Goodfellow Inc.). Table 1 provides the TZM composition given by the supplier.

The alumina purity was higher than 99 wt-\% with traces of sodium, silicon, magnesium, and calcium, due to sintering additives. After cutting, the disks were polished up to $\mathrm{Ra}=$ $0.06 \mu \mathrm{m}$ using SiC paper (4000 mesh).

For the oxidation treatment in air, the TZM disks were simply placed onto the alumina disks inside a furnace for a thermal cycle with the dwell time of $30 \mathrm{~min}$ at $795^{\circ} \mathrm{C}$, reached with the rate of $30^{\circ} \mathrm{C} \mathrm{min}-1$, and followed by the slow temperature decrease $\left(30^{\circ} \mathrm{C} \mathrm{min}-1\right)$, for relaxing, at least partially, the possible interfacial shear stresses.

After this first treatment, the samples were put in a graphite die, the edges of which were protected by Papyex ${ }^{\circledR}$ sheets (flexible graphite provided by MERSEN, France). The samples were then hot pressed under $22 \mathrm{MPa}$ at $1700^{\circ} \mathrm{C}$ in argon flow (1.9 $\mathrm{L} \mathrm{min}^{-1}$ ) using a furnace (LPA Goliath, France) with a graphite resistor and a uniaxial single-acting

Table 1 - TZM Alloy Composition

$\begin{array}{cllccccc}\text { Element } & \text { Mo } & \mathrm{Ti} & \mathrm{Zr} & \mathrm{C} & \mathrm{W} & \mathrm{Fe} & \text { Other } \\ \text { at.-\% } & 99.3 & 0.5 & 0.07 & 0.05 & 0.02 & 0.005 & \text { Bal. }\end{array}$




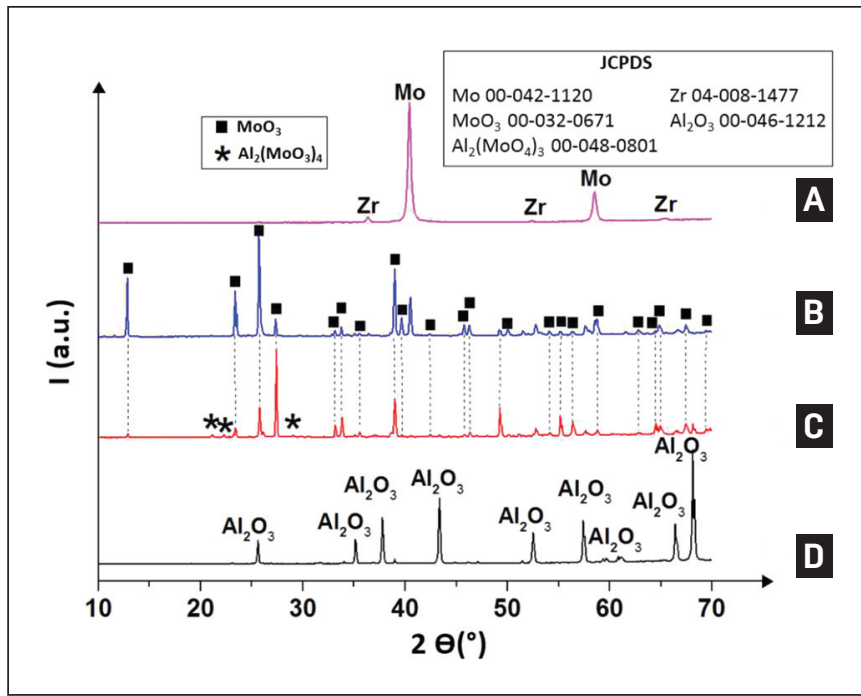

Fig. 2 - XRD patterns of TZM and alumina before and after the thermal treatment in air, with the corresponding JCPDS file numbers: $A-$ TZM raw material; $B$ - TZM side after oxidation in air; $C$ - alumina side after oxidation in air; $D-$ alumina raw material.

press. The thermal cycle comprised a temperature rise of $15^{\circ} \mathrm{C} \mathrm{min}^{-1}$ followed by a 3-h dwell; then, the pressure was released, and the furnace alimentation was stopped. Under these conditions, the samples cooled down to ambient in about $110 \mathrm{~min}$.

The assemblies were then observed with a JEOL IT 300 scanning electron microscope (SEM) and analyzed simultaneously with an energy-dispersive spectrometer (EDS, Oxford Instruments-INCA).

The x-ray diffraction patterns were obtained with a Bruker D8 Advance diffractometer, coupled with a copper anticathode and a backward monochromator. The scanned angles $(2 \theta)$ were in the range of $10-70$ deg with a step of 0.029 $\mathrm{deg}$, and the exposure time was $0.45 \mathrm{~s}$ per step. The identifications of phases were carried out with the International Centre for Diffraction Data database.

The tensile strength of the assemblies after hot pressing was determined by following the ASTM C633-13 standard test (Ref. 11) and using an Adamel-Lhomargy DY-26 traction apparatus. The assemblies were glued to two cylindrical C38 steel dollies with HTK Ultra Bond $100^{\circledR}$ (HTK, Hambourg, Germany) glue, and the pulling rate was $0.8 \mathrm{~mm} / \mathrm{min}$ (Ref. 3). Several other tests are commonly used to evaluate the tensile strength of ceramic-metal bonding, in particular the ASTMF19 method (or AWS C3.2, Standard Method for Evaluating the Strength of Brazed Joints). Although this testing method is widely used for measuring the tensile strength of metal-toceramic brazed joints, it has not been considered in this work. Due to the applied load (22 MPa) during the hot-pressing step, the geometry of the standard ASTM-F 19 tensile button samples was not suited for this bonding process.

\section{Results}

First, directly joining the alumina discs to the TZM by using hot pressing was attempted, at different temperatures $\left(1500^{\circ}-1700^{\circ} \mathrm{C}\right)$, without preoxidation. The assemblies ob-

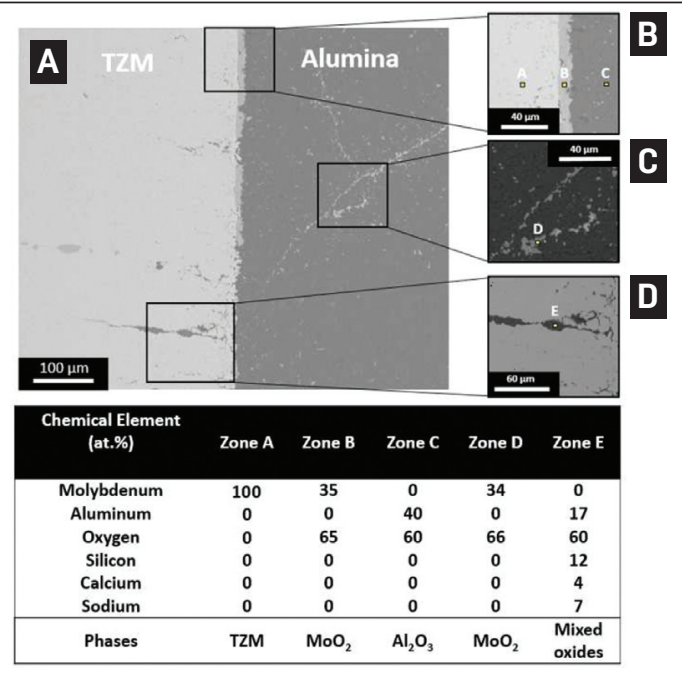

Fig. 3 - TZM/alumina assembly of SEM observations in the cross section after HP: A - General view; B - interfacial zone; $C-$ detail of the inclusions inside alumina; $D-T Z M$. The table gives the composition of the points $A, B, C$, and $D$ in Fig. $3 B-D$, measured by EDS.

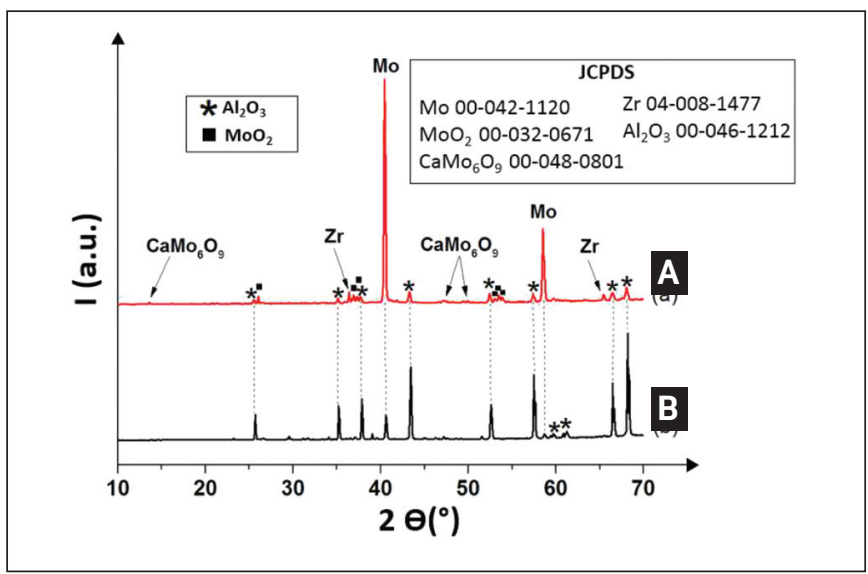

Fig. 4-XRD patterns of the interfacial zone after hot pressing and breaking the joint, with the corresponding JCPDS files numbers: A - TZM side; B - alumina side.

tained were extremely weak and could be easily hand broken. This result was expected, on the basis of the above thermodynamic considerations.

Hence the following experiments consisted of heating TZM placed onto the alumina discs under the conditions described previously, and then to use hot pressing.

\section{After the Preoxidation Treatment}

After the preoxidation treatment and before hot pressing, the assemblies were already achieved, but they had poor adherence and could be broken manually. After enclosing the samples in a protective resin, they were cut with a diamond saw. The SEM cross-section observation of the assembly, in backscattered electron (BSE) mode, is given in Fig. 1A, with the corresponding EDS analysis in Fig. 1B.

Four distinct zones are visible in Fig. 1A and in the diffu- 
sion profile of Fig. 1B, from the left to the right:

1) The nonoxidized TZM;

2) A crystalline oxide layer, approximately $120 \mu \mathrm{m}$ thick, identified by the EDS analysis as molybdenum trioxide $\mathrm{MoO}_{3}$ (the atomic contents of molybdenum and oxygen being, respectively, $25 \%$ and $75 \%$ );

3) Another zone also composed of a crystalline oxide layer, but denser than the previous one and about $80 \mu \mathrm{m}$ thick. This zone contains the elements molybdenum, oxygen, and aluminum, with composition shifts; molybdenum is the major metallic component at the left side and aluminum at the right side. The mean composition is about 17 at.-\% of molybdenum, 71 at.-\% of oxygen, and 12 at.-\% of aluminum that corresponds to the aluminum molybdate $\mathrm{Al}_{2}\left(\mathrm{MoO}_{4}\right)_{3}$. This zone results from the reaction between alumina and molybdenum trioxide, following Equation 2:

$$
3 \mathrm{MoO}_{3}+\mathrm{Al}_{2} \mathrm{O}_{3} \rightarrow \mathrm{Al}_{2}\left(\mathrm{MoO}_{4}\right)_{3}
$$

4) The rightmost zone is constituted of nonaffected alumina.

The assemblies were broken to analyze the surfaces of the junction zone. The XRD analyses of the corresponding surfaces are reported in Fig. 2 (Fig. 2B: TZM side, and Fig. $2 \mathrm{C}$ : alumina side), together with the XRD patterns of the raw materials (Fig. 2A: TZM, and Fig. 2D: alumina).

The raw TZM presented the major peaks of bcc molybdenum; some small peaks of zirconium were visible in certain XRD patterns, such as that of Fig. 2A, the other elements being not visible. Alumina was in the corundum variety $\left(\gamma-\mathrm{Al}_{2} \mathrm{O}_{3}\right)$, and the pattern also identified small amounts of the sintering additive $\mathrm{Mg}_{2} \mathrm{SiO}_{4}$.

Figure $2 \mathrm{~B}, \mathrm{C}$ confirmed the presence of the phase $\mathrm{MoO}_{3}$ in both sides of the junction (TZM and alumina sides), and traces of $\mathrm{Al}_{2}\left(\mathrm{MoO}_{4}\right)_{3}$ were also visible but only in the alumina side. All this meant that, when breaking, the rupture occurred inside $\mathrm{MoO}_{3}$.

\section{After Hot Pressing}

After hot pressing, TZM and alumina were very strongly linked. The SEM micrographs of the interfacial zone, reported in Fig. 3A (general view in BSE) and Fig. 3B-D (details) showed this zone looked very different than before the HP treatment (compare with Fig. 1A), mainly because the oxide interlayers had almost completely disappeared. Only a thin layer less than $10 \mu \mathrm{m}$ thick remained, in places, between the alloy and the alumina, such as in Fig. 3B EDS (point B of Fig. 3B), identified the oxide $\mathrm{MoO}_{2}$ alone.

Inside the TZM, many dark penetrations were visible inside the alloy, up to around $300 \mu \mathrm{m}$ from the interface (see Fig. 3A). The bright zones (e.g., the EDS analysis of point A in Fig. 3B) corresponded to molybdenum, while the dark zones (point E of Fig. 3D) were composed of mixed oxides, containing aluminum, silicon, sodium, and calcium, which obviously came from the secondary phase of alumina.

Inside alumina, the microanalysis of Fig. $3 \mathrm{~B}$ (zone $\mathrm{C}$ ) corresponded to the nominal composition of $\mathrm{Al}_{2} \mathrm{O}_{3}$, but there was also several clearer lines, crossing the whole alumina disc and looking like fissures, as seen in the BSE micrograph of Fig. 3A. These lines contained molybdenum oxide $\mathrm{MoO}_{2}$ (see the EDS analysis of point D in Fig. $3 C$ ) that probably penetrated during hot pressing in cracks caused by the pressure.

The XRD analyses of the TZM and alumina sides of the interfacial zone, after hot pressing, required breaking the junction, which necessitated the use of a hammer and a screwdriver placed at the level of the junction because the pieces were very strongly bonded. The results, given in Fig. 4 , confirmed the presence of traces of oxide $\mathrm{MoO}_{2}$ in the TZM side, accompanied by some traces of $\mathrm{CaMo}_{6} \mathrm{O}_{9}$, while the oxide $\mathrm{MoO}_{3}$ and the aluminum molybdate, initially present in the XRD patterns of Fig. 2, disappeared completely after hot pressing. The diffraction peaks of alumina were visible on the XRD patterns of the TZM side and molybdenum peaks were identified on the XRD patterns of the alumina side. This signified that the adherence of the junction was comparable to the cohesion of both materials.

To determine the adherence value of the joining, rupture tests were attempted with the usual test ASTM C633-13 (Ref. 11), but they did not succeed because the breakings always occurred inside the used glue, for values around 45 $\mathrm{MPa}$, instead of inside the samples, which meant the adherence of the assembly was higher than this value.

Referring to values commonly obtained in the case of ceramic-to-metal bonding by brazing methods (50-100 $\mathrm{MPa}$ [Ref. 12]), the adherence value of the system under study (45 $\mathrm{MPa}$ ) is rational.

Currently, experimental and modeling studies are in progress to determine the adhesion value of this aluminaTZM bonding.

\section{Discussion}

The first step of the process (molybdenum oxidation in air at $795^{\circ} \mathrm{C}$ and reaction with alumina) is relatively complex, but the reaction mechanism can be understood on the basis of the following elements:

1) Molybdenum begins to oxidize in oxygen from about $300^{\circ} \mathrm{C}$ (Ref. 13), when the other components of TZM react at higher temperatures. At $795^{\circ} \mathrm{C}$, the only oxide obtained is $\mathrm{MoO}_{3}$

2) The melting temperature of $\mathrm{MoO}_{3}$ is of $795^{\circ} \mathrm{C}$, which means it is in the liquid state or almost at the treatment temperature. Hence, this oxide can easily react with alumina, giving the mixed oxide $\mathrm{Al}_{2}\left(\mathrm{MoO}_{4}\right)_{3}$. More precisely, in the "zone 3" of Fig. 1, one may find $\mathrm{MoO}_{3}$ (left side) and $\mathrm{Al}_{2} \mathrm{O}_{3}$ (right side); the composition shifts of aluminum and molybdenum show this zone corresponds to the phase diagram $\mathrm{MoO}_{3} / \mathrm{Al}_{2} \mathrm{O}_{3}$;

3) The so-constituted assembly is relatively brittle and, when breaking, the rupture occurs inside the $\mathrm{MoO}_{3}$ layer, so that $\mathrm{MoO}_{3}$ is the major phase found in both sides of the broken pieces. Hence, $\mathrm{MoO}_{3}$ appears as the weak link of the chain $\mathrm{TZM} / \mathrm{MoO}_{3} / \mathrm{Al}_{\mathrm{x}} \mathrm{Mo}_{\mathrm{y}} \mathrm{O}_{\mathrm{z}} / \mathrm{Al}_{2} \mathrm{O}_{3}$ that composes the interfacial zone, $\mathrm{Al}_{\mathrm{x}} \mathrm{Mo}_{\mathrm{y}} \mathrm{O}_{\mathrm{z}}$ representing the different compositions of the phases in "zone 3" of Fig. 1.

At the beginning of hot pressing, the pressure is imposed before heating. Insofar as the alumina discs were thin and the contact zones not perfectly plane, alumina was broken. This was confirmed by the observations of samples having undergone just the pressure, without heating.

After hot pressing, the interlayer quasi disappeared, and this is obviously the consequence of the pressure effect. In- 
deed, during heating (up to $1700^{\circ} \mathrm{C}$ ), all the interlayer oxide phases become liquid, and they are driven away by the pressure; they mainly go inside the cracks and migrate to the edges of the assembly, and they end up onto the Papyex sheet. The interlayer that was initially about $200 \mu \mathrm{m}$ thick only subsists in a few places, with a thickness that does not exceed $10 \mu \mathrm{m}$.

The nature and the localization of the remaining secondary phases must be explained.

1) Regarding the composition of the remains of the interlayer, after the oxidation step, the interlayer was composed of $\mathrm{MoO}_{3}$ and of mixed oxides $\mathrm{Al}_{\mathrm{x}} \mathrm{Mo}_{\mathrm{y}} \mathrm{O}_{\mathrm{z}}$, and after hot pressing it was only composed of the oxide $\mathrm{MoO}_{2}$. The explanation lies in the fact the oxides of the original interlayer are not stable at high temperatures, giving the demixing of the mixed oxides, and the conversion of $\mathrm{MoO}_{3}$ into $\mathrm{MoO}_{2}$. Some traces of $\mathrm{CaMo}_{6} \mathrm{O}_{9}$ were also found, and the only calcium source possible in the assembly being the sintering additives present in alumina, it must be concluded that these additives, more or less molten at $1700^{\circ} \mathrm{C}$, were driven off the grain boundaries of alumina and partially reacted with $\mathrm{MoO}_{2}$.

2) About the presence of $\mathrm{MoO}_{2}$ deep inside $\mathrm{Al}_{2} \mathrm{O}_{3}, \mathrm{MoO}_{2}$ melts at about $1100^{\circ} \mathrm{C}$, and consequently this phase was liquid before reaching the hot-pressing temperature and the molten $\mathrm{MoO}_{2}$, driven off the interface by the pressure filled the alumina cracks.

3) About the presence of oxides inside the TZM, first, the composition of these phases is surprising since they contain the elements $\mathrm{Ca}, \mathrm{Si}$, and $\mathrm{Na}$ that can only come from the grain boundaries of alumina. It must be deduced that the pressure drives off the secondary phase of alumina so that these phases penetrate inside the TZM, either through the grain boundaries but perhaps also through some fissures possibly formed inside this material.

From all this, a mechanism can be proposed for justifying the joining after the hot-pressing step. First, because the pressure of $22 \mathrm{MPa}$ was imposed before heating, the thin alumina disc was broken, and perhaps also that some fissures took place inside the TZM. Then, when heating, the interlayer melted, with decomposition and/or demixing, and the liquid phases left the interface under the pressure effect, went to the edge of the assembly or penetrated inside the alumina cracks. During the temperature increase, the liquid phase remained only in some places where the two discs of TZM and alumina were not perfectly in contact. When the highest temperature was reached $\left(1700^{\circ} \mathrm{C}\right)$, the pressure expelled the sintering additives from the alumina; they either reacted with $\mathrm{MoO}_{2}$ when this phase was still present, to give phases such as $\mathrm{CaMo}_{6} \mathrm{O}_{9}$, or they penetrated inside in the TZM via the grain boundaries or some fissures.

After cooling, TZM and alumina remained strongly bonded because of the interweaving of the two materials in the interfacial zone, due to the roughness of the interface. The secondary phases certainly played a role; they constitute sorts of nails crossing the interface that contributed to keep the pieces joined together.

It can be reminded that the interlayer is always the most brittle zone in the ceramic-to-metal junctions, and that, for this reason, it is better for this layer to be thin (Ref. 14). Hence, here, the quasi complete removal of the oxide from the interfacial zone is a further favorable point explaining the strength of the joining.

From the industrial point of view, this process presents the major interest to give a strong junction ceramic/metal, under relatively simple conditions, i.e., without the multiple steps of the active brazing processes. On the other hand, hot pressing is not a common process and can only be used for pieces having flat or almost flat geometry. One may also ponder the necessity of forming so many oxide phases during the preoxidation treatment, since these phases are quasi-entirely eliminated during HP. However, the role of the preoxidation step is also to make rough the surfaces of the alloy and of the ceramic, which is essential for obtaining a good joint. In these conditions, only empirical studies can allow optimizing this process.

\section{Conclusions}

The process used for joining alumina to TZM with only two steps (TZM preoxidation in air and hot pressing) gives strong junctions with adherence too high to be measured in the usual conditions of the adhesion test ASTM C633-13, but higher than $45 \mathrm{MPa}$.

The mechanical resistance of the junction is explained by two major and complex contributions:

1) A mechanical contribution: The interfacial zone, initially smooth, becomes irregular because of the reaction of oxygen with the alloy during the preoxidation (TZM side), and because of the formation of aluminum molybdate that attacks alumina (alumina side). After HP and after the oxide interlayer was lost, the ceramic and the metallic phases are in direct contact, but interweaved, and this feature favors the mechanical hooking of both materials (Ref. 15);

2) A chemical contribution: During hot pressing, several secondary phases penetrated in TZM and in alumina, which constitute sorts of small bars inside both these materials, crossing the interface and joining them together, as in the case of W/AlN assemblies (Ref. 16).

For optimizing this process, it should be necessary to define the optimal thickness of the oxide layer, the role of which is double; first, to attack the TZM and alumina surfaces and make them rough to allow the mechanical joining, and second, to allow the chemical reactions with the secondary phases that constitute the chemical contribution to the joining.

\section{Acknowledgments}

The authors gratefully acknowledge the French Education and Research Ministery for R. Berkouch's PhD scholarships.

\section{References}

1. Nicholas, M. G., and Mortimer, D. A. 1985. Ceramic/metal joining for structural applications. Material Science and Technology 1: 657-665. DOI: $10.1179 / \mathrm{mst} .1985 .1 .9 .657$

2. Hausner, S., and Wielage, B. 2013. Brazing of metal and ceramics joints. Advances in Brazing: Science, Technology and Applications, ed. by D. P. Sekulic. Cambridge, UK: Woodhead Publishing. p. 361. DOI: $10.1533 / 9780857096500$ 
3. Bernardie, R., Valette, S., Absi, J., and Lefort, P. 2015. Mechanical characterization of alumina coatings on C35 steel. Surface and Coatings Technology 276: 677-685. DOI: 10.1016/j.surfcoat. 2015.06.001

4. Williams, J. C., and Nielsen, J. W. 1959. Wetting of original and metallized high-alumina surfaces by molten brazing solders. Journal of the American Ceramic Society 42: 229-235. DOI: 10.1111/j.1151-2916.1959.tb15458.x

5. Hanson, W. B., Ironsid, K. I., and Fernie, J. A. 2000. Active metal brazing of zirconia. Acta Materialia 48: 4673-4676. DOI: 10.1016/S1359-6454(00)00256-1

6. Han, G. H., Bian, H., Zhao, H. Y., Song, X. G., Li, Y., Liu, J., Cao, J., and Feng, J. C. 2018. Interfacial microstructure and mechanical properties of TZM alloy and $\mathrm{ZrC}$ particle reinforced tungsten composite joint brazed using Ti-61Ni filler. Journal of Alloys and Compounds 747: 266-275. DOI: 10.1016/j.jallcom.2018.02.258

7. Yang, S., and Kang, S. H. J. 2000. Fracture behavior and reliability of brazed alumina joints via Mo-Mn process and active metal brazing. Materials Research 15: 2238-2245. DOI: 10.1557/ JMR.2000.0321

8. Berkouch, R., Valette, S., Absi, J., and Lefort, P. 2018. A new method for bonding alumina to the alloy titanium-zirconiummolybdenum. Journal of the European Ceramic Society 38: 24622466. DOI: 10.1016/j.jeurceramsoc.2018.01.004

9. Barin, I., and Knacke, O. 1973. Thermochemical Properties of Inorganic Substances. Düsseldorf, Germany: Springer-Verlag. DOI: 10.1002/bbpc.19750790122

10. Economos, G., and Kingery, W. D. 1953. Metal-ceramic interactions: Metal-oxide interfacial reactions at elevated temperatures. Journal of the American Ceramic Society 36: 403-409. DOI: 10.1111/j.1151-2916.1953.tb12829.x
11. ASTM C633-13, Standard Test Method for Adhesion or Cohesion Strength of Thermal Spray Coatings. ASTM International, West Conshohocken, Pa. 2013. DOI: 10.1520/C0633-13R17

12. Walker, C. A., and Hodges, V. C. 2008. Comparing metalceramic brazing methods. Welding Journal 87(10): 43-s to 50-s.

13. Jörg, T., Hofer, A. M., Köstenbauer, H., Winkler, J., and Mitterer, C. 2018. Oxidation and wet etching behavior of sputtered Mo-Ti-Al films. Journal of Vacuum Science and Technology A: Vacuum, Surfaces and Films 36(2): 021513. DOI: 10.1116/1.5009289

14. Erskine, K. M., Meier, A. M., Joshi V. V., and Pilgrim, S. M. 2014. The effect of braze interlayer thickness on the mechanical strength of alumina brazed with $\mathrm{Ag}-\mathrm{CuO}$ braze alloys. Advanced Engineering Materials 16: 1442-447. DOI: 10.1002/adem.201400128

15. Mellali, M., Fauchais, P., and Grimaud, A. 1996. Influence of substrate roughness and temperature on the adhesion/cohesion of alumina coatings. Surface and Coatings Technology 81: 275-286. DOI: 10.1016/0257-8972(95)02540-5

16. Lefort, P., and Quériaud, R. 1994. Compatibility between molybdenum and aluminum nitride. Journal of the European Ceramic Society 13: 329-333. DOI: 10.1016/0955-2219(94)90007-8

RÉDA BERKOUCH is a PhD student, STÉPHANE VALETTE (stephane.valette@unilim.fr) is an assistant professor, and JOSEPH ABSI and PIERRE LEFORT are professors, at the University of Limoges, Institute for Ceramic Research, National Center for Scientific Research, Limoges, France.

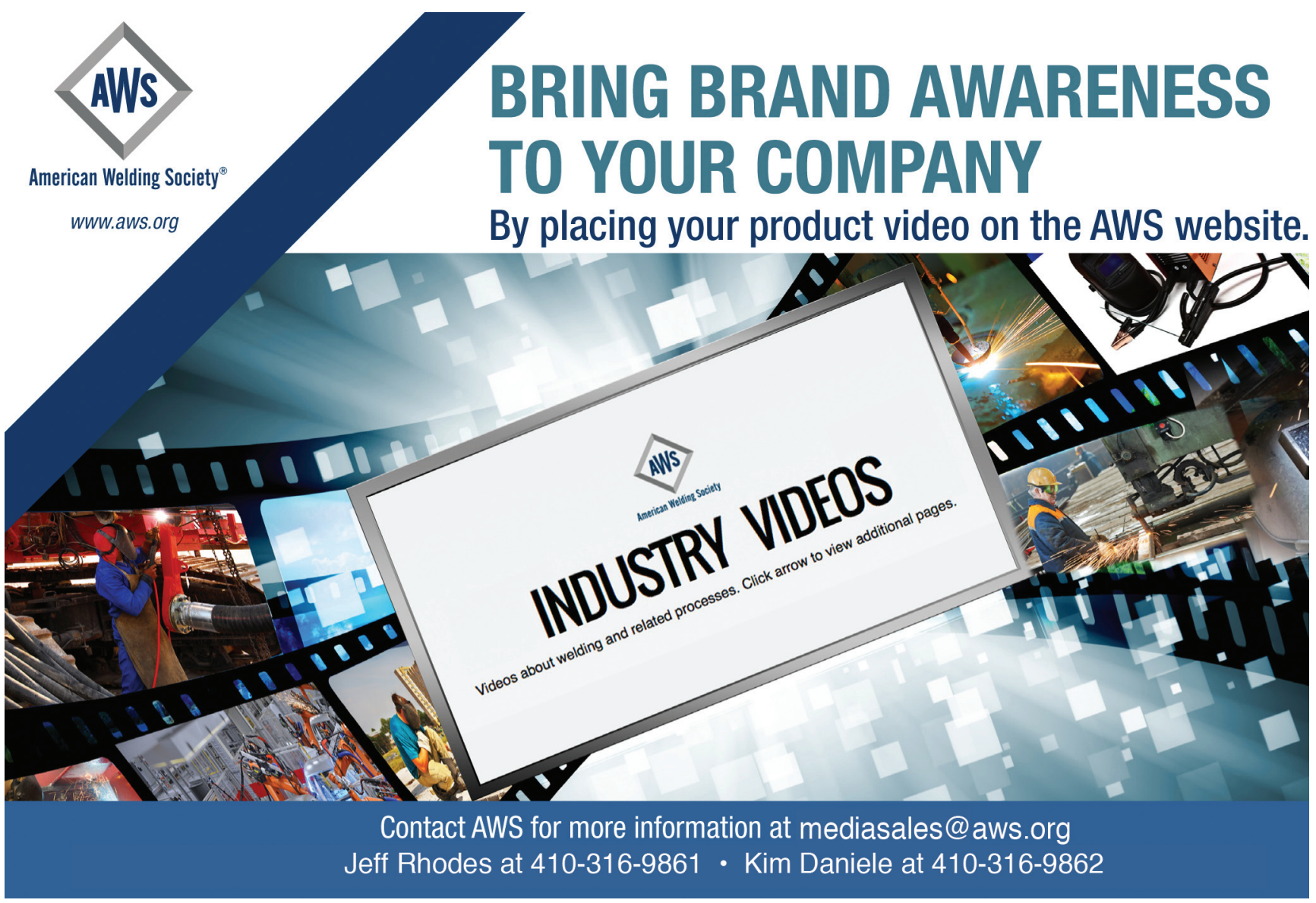

